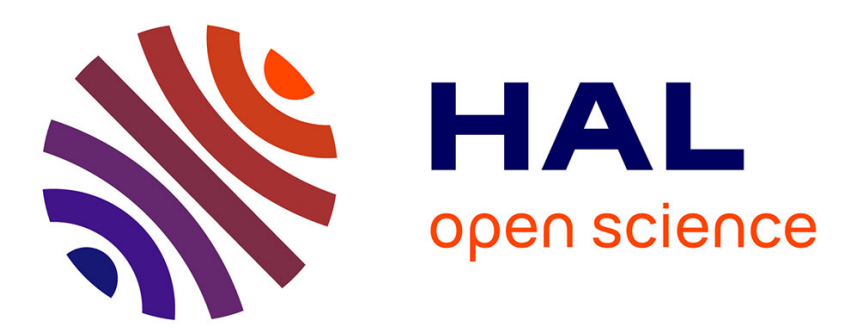

\title{
Pull control for Job Shop: Holonic Manufacturing System approach using multicriteria decision-making Fouzia Ounnar, Patrick Pujo
}

\section{To cite this version:}

Fouzia Ounnar, Patrick Pujo. Pull control for Job Shop: Holonic Manufacturing System approach using multicriteria decision-making. Journal of Intelligent Manufacturing, 2012, 23 (1), pp.141-153. 10.1007/s10845-009-0288-4 . hal-01212608

\section{HAL Id: hal-01212608 https://hal.science/hal-01212608}

Submitted on 18 Oct 2015

HAL is a multi-disciplinary open access archive for the deposit and dissemination of scientific research documents, whether they are published or not. The documents may come from teaching and research institutions in France or abroad, or from public or private research centers.
L'archive ouverte pluridisciplinaire HAL, est destinée au dépôt et à la diffusion de documents scientifiques de niveau recherche, publiés ou non, émanant des établissements d'enseignement et de recherche français ou étrangers, des laboratoires publics ou privés. 


\title{
Pull control for Job Shop: \\ HMS approach using multicriteria decision-making
}

\author{
F. Ounnar ${ }^{1}$, P. Pujo \\ Laboratoire des Sciences de l'Information et des Systèmes (LSIS) \\ UMR CNRS 6168 \\ Aix Marseille Université \\ Avenue Escadrille Normandie Niemen \\ 13397 Marseille Cedex 20 - France \\ Phone: (33) 0491056010 \\ Fax: (33) 0491056033 \\ E-mail: \{fouzia.ounnar, patrick.pujo \}
}

\begin{abstract}
Faced with international competition, industrial production increasingly requires implementation conditions which, in some cases, lead to seek new techniques for workshop control. This is the case when it is asked to establish Just in Time management in a Job Shop having the characteristics of working with small series. A new approach for the organization of the 'control' function in such a context is presented here. This approach relies on the use of the holonic paradigm on an isoarchic architecture and on a decision-making capacity based on a multicriteria analysis. The various concepts of this approach are addressed first. Then, the multicriteria decision mechanisms that are used are detailed, as well as the implementation and instrumentation phases. The first results that were obtained are presented.
\end{abstract}

Keywords: Pull system, Job Shop, Isoarchic Control, Holonic Manufacturing System, PROSIS, Multicriteria decision aid methods (Analytic Hierarchy Process).

\footnotetext{
${ }^{1}$ Corresponding author
} 


\section{INTRODUCTION}

New workshop control techniques are necessary to meet the more and more demanding requirements of industrial production of small and medium sized series. A research direction consists in getting inspired from pull flow techniques which were essential in mass production. Some people recommend a lean approach allowing working in Just in Time with very small series. However, lean tools such as heijunka or visual management are essentially based on training and experiment and lack formalism and $\backslash$ or scientific rigour. We present in this paper a radically innovative manner to organize the operation control of a Job Shop.

After presenting first the concepts that are at the basis of control system operations for manufacturing systems and their recent evolutions, we address the better known approaches and we present more specifically Holonic Manufacturing Systems (HMS) and the holonic architecture PROSA (Product, Resource, Order, Staff Architecture). We then describe our own holonic approach, affiliated to PROSA, which is based on an isoarchic decisional structure and a decision-making process based on a multicriteria analysis and which contains the three basic holons of PROSA: Product Holon (PH), Resource Holon ( $\mathrm{RH})$ and Order Holon $(\mathrm{OH})$. We consider that control decision-making requires the participation of all entities (Products, Resources and Orders). These various entities do not all seek the same objective; it is thus necessary to find the best possible compromise allowing deriving a control solution that is "contextually" optimal. Faced with this problem, we turned to the use of multicriteria decision aid methods which allow taking into account and lor reconciling contradictory interests. For pulling flows in a Job Shop, it is not possible to use the same techniques as for mass production lines in which Work In Progress (WIP) levels (i.e. the number of kanbans present in the schedule) are used as control instructions.

In order to mitigate this difficulty, we have developed a strategy to artificially create a pull flow effect. One of the criteria, considered as fundamental in our multicriteria analysis, allows favouring products whose progress state is close to the final state. The closer to its completion the product is, the more important the priority of this product is. Two indicators were identified to take this criterion into account, an indicator related to product global progress and a local progress indicator. These indicators allow favouring the flows throughout a 'virtual production line' associated to product routing (the downstream call is triggered by the product itself). There are then as many virtual lines working in parallel in the workshop as there are WIP types. The products contribute first to emptying the production system, which releases capacity that can be used by resources, and then to facilitating a product flow when the next resource to handle this product will treat it quickly.

After presenting the way the pull flow can be set up in a Job Shop through multicriteria decision-making mechanisms, we present the first experiments which show that very good performances have been obtained with this approach.

\section{HOLONIC AND ISOARCHIC CONTROL}

\subsection{Evolution of production system control}

Control systems are in perpetual evolution. We present here how new control approaches are currently developed starting from conventional control and how our approach differs from these approaches. Production activities are generally organized by hierarchical decomposition and successive refinements of the tasks to be carried out (Mesarović et al., 1980). At the lower decisional level of a workshop, operational control must indicate in a precise way the actions to be done in the short term. This must be often carried out in real time in order to be able to obtain an effective and efficient operation of the production system. Activities of this organization are generated by a planning carried out off line and in a precise way, leading to a scheduling of the workshop operation: this is estimated control. Contingent events disturbing the initial plan appear during effective task implementation in the workshop. The role 
of the control is then to find on line a solution allowing continuing the workshop operation while preserving acceptable performances. This operational aspect of control is more and more often carried out by a MES (Manufacturing Execution System), on the basis of re-scheduling tasks for the ad hoc resources.

Since some time, a scientific community has emerged around systems controlled by products. (Mathews, 1995) mentions the holonic paradigm which, in the field of HMS (Holonic Manufacturing Systems), is not reduced to only a vision oriented product. We fully join this vision related to the evolution of control systems. In our viewpoint, control by products of production systems is not sufficient. Indeed, a product does not carry all the operational constraints and all associated information needed to make optimal, or at least satisfactory, control decisions. This position is largely consolidated by the work of the IMS (Intelligent Manufacturing System) community, which focuses on the identification of the various types of entities which are interacting in a manufacturing production system. Each of these entities brings its own data file and its own constraints, thus constituting a viewpoint. It is by taking into account all the data and constraints, sometimes contradictory, that one can generate the best possible solution at a given time. This is why we propose a control that integrates multiple viewpoints and results from various types of interacting entities. HMS results conceptually agree with this proposal.

\subsection{Holonic and isoarchic architecture of the control}

The holonic paradigm was initially proposed by (Kostler, 1967) for modelling complex social systems. In such systems, an entity (a holon) is at the same time a whole and part of a whole (Janus effect). This approach marks a rupture with former hierarchical models. Indeed, a holon has a decisional intelligence which enables it to act on its own behaviour, but which also enables it to intervene on the behaviour of the system it belongs to (Pujo and Ounnar, 2007). The hierarchical decomposition is replaced by the recursion of holons and the implementation of the Janus effect. Various holonic architectures are proposed in the scientific literature for HMS control. The best known is PROSA (Van Brussel et al., 1998). The other architectures do not offer possibilities to describe completely decentralized systems: ADACOR (Leitão et al., 2006) adds to the basic PROSA holons a supervisory holon in charge of coordination and optimization in a group of holons: it is a local and centralized decision-making centre; MetaMorph (Maturana et al., 1999) is a holonic control architecture based on a control via a set of mediators which are centralized decision-making centres. We used the core of PROSA made of 3 types of basic holons: Product Holon (PH), Resource Holon (RH) and Order Holon (OH).

The development of control systems disregarding the concepts of hierarchy and centralization gradually resulted in passing from the idea of decentralization (Brun-Picard, 1988) to the concept of selforganization (Pujo and Ounnar, 2007) and then in developing the isoarchy concept, thus revisiting the use of some concepts proposed by PROSA.

A control system which is at the same time decentralized and self-organized can be characterized as isoarchic. The definition of 'isoarchy' can be envisaged from the two Greek radicals: isos (equal) and arkhes (ruler), thus meaning the same authority and total absence of hierarchy. In a decision system composed of several decision-making centres, a decisional architecture can be described as isoarchic when each decision-making centre is equipped with the same decision capacity. This property can be easily obtained when the decision mechanisms are duplicated on each decision-making centre and are parameterized according to the characteristics of each one. Isoarchy appears then as a particular specification of the heterarchy concept and the absolute opposite to the hierarchy concept (Mesarovic et al., 1980). The scientific discussions on control architectural structures are situated in a linguistic space: 'centralized/hierarchically' to 'decentralized/self-organized'. This space includes of course all the intermediate solutions. This has collateral damages because there is not any more an exclusive term contrary to 'centralization'. For example, the term 'heterarchical' used for some time is now applied to 
distributed architectures on several decision levels, with local hierarchical decisions. Finally, the concept of isoarchy should only be used on really and completely egalitarian and self-organized architectures.

The isoarchic approach can be implemented via the holonic paradigm, given specific software developments. For that, the approach initially proposed by PROSA will be extended and particularized in the next section with the presentation of PROSIS (Product, Resource, Order \& Simulation Isoarchic Structure).

\section{The PROSIS approach}

\subsection{Implementation of a holonic approach in an isoarchic context}

In a complex system composed of entities having decisional capacities, isoarchy is characterized by the fact that all the decisions are taken through the autonomy of these entities. This requires a direct communication capacity between entities to effectively solve synchronization, coordination and/or cooperation problems. The isoarchic structure of the decision centres offers this possibility: various holons jointly ensure the decisions that concern them in interactions via a common communication protocol, without instruction or order coming from higher level entities. This concept of isoarchy can be implemented via the holonic paradigm: it can be noticed that the concept of 'Flat Holonic Form' (Bongaerts et al., 2000) is an isoarchical particularization of holonic architecture. In addition, the absence of a central decision system prohibits any preset or estimated organization of workshop control, which is progressively organized by the entities. Self-organization implies a real time character which takes into account all information characterizing each entity contributing to the establishment of the operation. The self-organized control functions are integrated in the intelligence associated to each entity (or holon): the authors define a Holon as a conceptual entity based on the association of a given Material Structure (M_holon) with an Information System, providing the whole with a Decisional Intelligence giving the capability to operate in interaction with other holons (I_holon) (Figure 1).

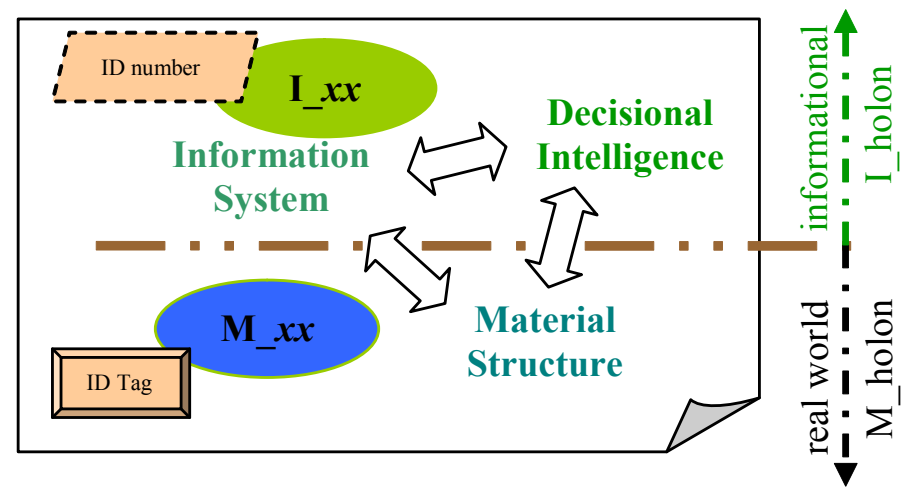

Figure 1. Basic structure of $x x$ Holon

This structuring allows a recursive decomposition of production systems, in agreement with the holonic paradigm, while clearly revealing the duality and parallelism between the physical world (material) and the informational world (immaterial, where decision-making is situated).

\subsection{Product, Resource, Order \& Simulation Isoarchic Structure}

The PROSIS concepts inherit from the PROSA basic concepts (Product Holon, Resource Holon and Order Holon). 
A Product Holon ( $\mathrm{PH}$ ) consists of a material product (the physical part) and an informational product (the immaterial part) called I_Product. This I_Product contains the product manufacturing process data and also its state model and all information concerning its traceability. There are thus as many PHs as manufactured products or as products in WIP. This is a major difference with PROSA. Unit identification requires the deployment of ad hoc technologies, a good example of which being RFID (Radio Frequency IDentification). An ID Tag is fixed on the manufactured product (Figure 1). This Tag contains information ranging - depending on the technology implemented and its memory size - from a single identification number to all the data relating to this manufactured product: single identifier, technical description data (dimensions, routing, etc), traceability and quality control data, optimization criteria specific to this product, etc.

An Order Holon $(\mathrm{OH})$ represents a task in the production system: a work order concerns a set of PHs. It is thus closely related to the concepts of batch, WIP and lead times. A product order is associated to each task. Concretely, the order sheet or the container, the pallet or the case is equipped with an ID Tag. This allows synchronisation with the I_Order, which ensures, during completion of the work, lead times satisfaction as well as consideration of economic factors (batch size, WIP quantities, minimization of production changes, split batches, etc).

A Resource Holon (RH) remains conceptually similar to the definition of PROSA. The resource includes the mechanical part of the equipment and its numerical control rack. Resource allocation methods of the I_resource evolve compared to PROSA, since interactions with the other types of holons are different in an isoarchic context. The I_resource also manages the activity planning of the resource, triggers task execution via the $\mathrm{NC}$ rack, saves the resource activity history and updates a set of local production indicators, such as OOE (Overall Equipment Effectiveness).

A Simulation Holon is added to show and evaluate the prospects for evolution of the production system with time. Indeed, the main difficulty with a self-organized decision system is the lack of visibility on future activities, due to the absence of planning and scheduling. Even if an estimated planning is used, it turns out to be disturbed when used and presents all the same a falsely reassuring character for the operators and their management. The objective of this paper is not to develop this aspect of PROSIS. Therefore, the Simulation Holon will be mentioned only briefly: it contains the behavioural models of all the holons present in the production system and updates their respective states starting from the analysis of the messages exchanged between them. Any significant change of state of the production system results in a new initial state allowing launching a 'warm up' simulation. This gives an insight into what may be likely to occur in the production system, and possibly corrects anomalies before they emerge.

\subsection{Ambient Control Entity}

Self-organization implies that control decisions must be made locally. Each resource is surrounded by 1 I_resource, $\mathrm{p}$ I_products and k I_orders corresponding to products $(\mathrm{k} \leq \mathrm{p})$. Decision making in control becomes then a problem requiring the participation of all the entities: resources, orders and products. For that, local and specific interactions are established between the I $x x$ of the $(1+\mathrm{p}+\mathrm{k})$ concerned holons. These holons constitute a 'Flat Holonic Form'. It clearly appears that these various holons do not all aim at the same objective and that the best possible compromise should be achieved for a control solution to be a good solution in this context. Faced with this problem, control is achieved through the support of an Ambient Control Entity (ACE) associated to each resource and giving intelligence and decision making power to the holonic entities. Intelligence is referred to as ambient because of the omnipresence of wireless communicating non apparent computing agents. Each ACE provides local I_Holons with various ad hoc services. Figure 2 shows a structural view of such an ACE. 


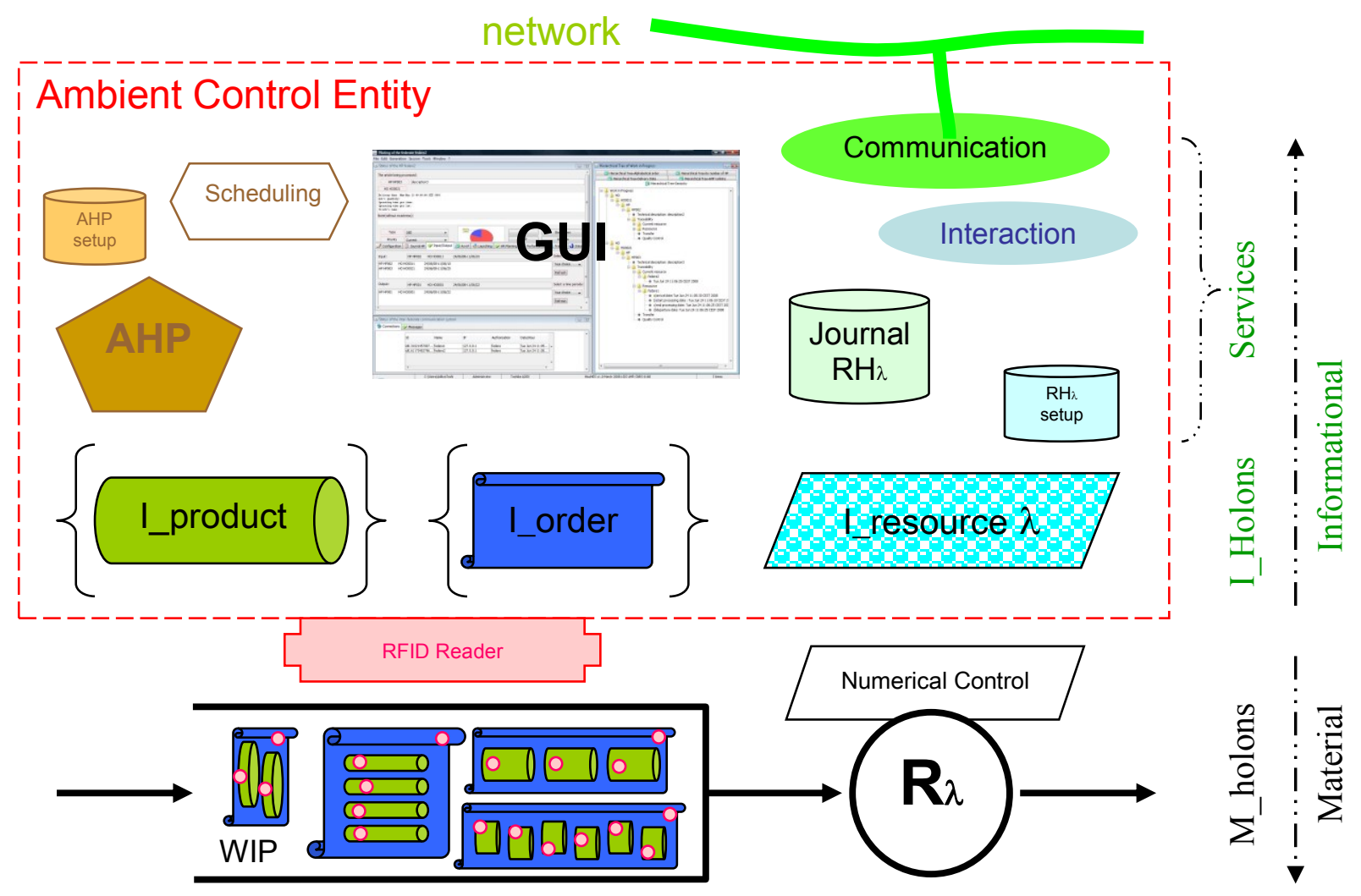

Figure 2. Structural view of an ACE

The problem of self-organization is based on how product flows are built in real time. In fact, the true problem is the fate of the product being processed onto the resource, i.e. which resource will be in charge of the next stage or which product will be processed by a given resource.

The necessary data needed for the implementation of these cases come from interactions between the concerned holons. The study of the functions supported by an ACE allows a better understanding of how these interactions are facilitated.

Several functional services are common to all ACEs, whatever their application. Several services make an ACE: Communication, hosting the I_holons corresponding to the M_holons in the WIP, Interaction, Optimization, Graphical User Interface, RFID reader \& writer.

The Communication service ensures the link with the others ACEs, and with the I holons that are present in these ACEs. It deals with all the technological aspects involved in the use of an industrial communication network: message formatting, data transmission and monitoring of message transmission quality.

An ACE allows hosting the $(1+p+k)$ I_holons and supports their interactions. It updates the WIP state of each resource. For that, each ACE is equipped with a RFID reader, which permits synchronization between the physical world and the information system: when a product or a batch of products arrives in the WIP of a resource (or leaves it), the corresponding ID tag is read and the whole set \{I product, I_order $\}$ is updated (added to or withdrawn from the ACE information structure).

The Interaction service allows task assignment by calling for a competition between the resources that are potentially able to respond to a CFP. In order to obtain a coherent result, it is necessary to implement a decision protocol based on impartial and common rules and criteria. This decision mechanism belongs to the interaction protocol family of the Contract Net family (Smith, 1980; Hsieh, 2008; Ounnar, 2008). It consists in identifying, within a network of entities, the one that gives the best response to a Call For Proposals (CFP): this is the entity that will be entrusted with the execution of the corresponding task. 
The interaction service analyzes the messages it receive and, when a CFP concern the entity, triggers the processing enabling the entity to respond in the best possible way.

For that, the Optimization service allows the ACE to self-evaluate the capacity of the resource to carry out the task described in the received Call For Proposals: the ACE estimates its own performance in order to be able to respond. The optimization service is based on the multicriteria decision aid method AHP (Analytic Hierarchy Process). This service elaborates the best possible solution, by taking into account the technical characteristics of the resource - which limits its performance - and its availabilities. All this implies a very strong relationship between the Optimisation service of the ACE and the different Holons associated with this ACE: the Holon Resource, of course, but also the Product Holons and the Order Holons.

\section{MULTICRITERIA DECISION MAKING FOR HOLONIC AND ISOARCHIC CONTROL}

We can distinguish between three classes of multicriteria methods: decision aid methods, elementary methods and mathematical optimization methods. The choice of one class of methods can depend either on the data available to treat the multicriteria problem, or on the way the decision maker models his preferences. In our case, the selection process of the product to be processed by a resource supposes knowledge of the various possible alternatives in order to carry out sorting with respect to a set of criteria. So, the use of optimization methods is not possible. In addition, the objective being to carry out a classification, the elementary methods are not considered. Multicriteria decision aid methods make it possible to bring help to the decision maker during the refinement of his decision-making process related to the choice of an alternative among a set of potential alternatives. All the products in the resource queue (WIP) constitute the alternative set. Classification of the alternatives is carried out by examining the logic and the coherence of the choices and by aggregating the preferences according to one of three approaches: complete, partial or local. In our case, complete aggregation is applied to classify all the products in the resource WIP. We chose the Analytic Hierarchy Process method (AHP) (Saaty, 1980) because AHP has advantages over other decision-making approaches (Vargas 1990, Wedley 1990), which include ability (i) to handle qualitative and quantitative attributes; (ii) to hierarchically structure problems to gain insights into the decision-making process; and (iii) to monitor the judgement consistency of a decision-maker. AHP was chosen as the multicriteria method because of its capability to quantify and rank the alternatives using pair wise comparison of criteria (Harker 1989). All these characteristics make the strong points of the AHP method (Ounnar, 1999; Ounnar et al, 2007). AHP has demonstrated robustness across a range of application domains.

A multicriteria decision making algorithm applying AHP is established in each RH and defines a $\mathrm{PH}$ classification, taking into account $\mathrm{RH}, \mathrm{PH}$ and $\mathrm{OH}$ constraints. Only the product ranked in first position is interesting: it is the next one to be processed by the resource.

We propose to implement AHP through two main phases: configuration and exploitation.

In order to be able to use the AHP algorithm for ranking the products placed in the queues, it is first necessary to define the relative importance of the criteria and their indicators: this is the setup (configuration) phase. Pair wise comparison between the various criteria $C_{j}$ compared to their importance in the PH decision is performed. This 'static' phase of the algorithm must be validated by mathematical coherence checking. First of all, it is necessary to classify the criteria in regard to a global objective.

For that we build a matrix [C] in which each element $c_{i j}$ is a judgement or a comparison between a pair of criteria $C_{i}$ and $C_{j}$, according to a scale going from 1 to 9 (Table 1 ), with $c_{i j}=1 / c_{j i} \& c_{i i}=1$. This matrix makes it possible to determine the relative importance vector $\left[\mathrm{V}_{\mathrm{COg}}\right]$. Coherence checking allows detecting and correcting the affected weights. Then, a classification of each indicator $\mathrm{I}_{\mathrm{k}, \mathrm{i}}$ is established according to its $\mathrm{C}_{\mathrm{k}}$ criterion, for the whole set of $\mathrm{C}_{\mathrm{k}}$ criteria. For this purpose, a matrix $\left[\mathrm{I}_{\mathrm{Ck}}\right]$ is built in which each element $i_{k, i j}$ is a judgement or a comparison between a pair of indicators $I_{k, i}$, and $I_{k, j}$. For 
each matrix $\left[\mathrm{I}_{\mathrm{Ck}}\right]$, the relative importance vector $\left[\mathrm{V}_{\mathrm{ICk}}\right]$ is estimated according to the same principle with validation of matrix $\left[\mathrm{I}_{\mathrm{Ck}}\right]$ consistency. This initialization phase must be validated for each new configuration of parameters.

\begin{tabular}{|c|c|}
\hline $\begin{array}{c}\text { Numerical } \\
\text { Values }\end{array}$ & Definition \\
\hline 1 & Equally important \\
3 & Slightly more important \\
5 & Strongly more important \\
7 & Very strongly more important \\
9 & Extremely more important \\
Reciprocals & Used to reflect dominance of the second \\
& alternative as compared with the first. \\
\hline
\end{tabular}

Table 1. Scale of Measurement for AHP (Saaty, 1980)

The dynamic exploitation phase of the AHP algorithm makes it possible to rank the PHs in the queue. First, a $\mathrm{PH}$ classification is established by comparing each $\mathrm{I}_{\mathrm{kx}}$ indicator of each criterion $\mathrm{C}_{\mathrm{k}}$. For each indicator, we compare pair to pair indicator values between the PHs of the queue. A matrix [ $\left.\mathrm{P}_{\mathrm{kx}}\right]$ is built with: $p_{k x ; i j}=I_{k x, j} / I_{k x, i}$ to minimize the criterion and with $p_{k x ; i j}=I_{k x, i} / I_{k x, j}$ to maximize the criterion, $p_{k x ; i j}=$ $1 / p_{\mathrm{kx} ; \mathrm{ii}}$ and $\mathrm{p}_{\mathrm{k} x ; \mathrm{ii}}=1$. The relative importance vector $\left[\mathrm{V}_{\mathrm{Plk}, \mathrm{X}}\right]$ between the PHs can then de calculated. Then, it is necessary to go up in the hierarchy of relative choices because the goal is to determine the relative importance of the PHs in regard to a global objective. A matrix $\left[\mathrm{PI}_{\mathrm{k}}\right]$ is built, in which each column is a vector $\left[\mathrm{V}_{\mathrm{PI}, \mathrm{X}}\right]$. A vector giving the relative importance of the products compared to the criteria is built, and this, for each criterion: $\left[\mathrm{PC}_{\mathrm{k}}\right]=\left[\mathrm{PI}_{\mathrm{k}}\right] *\left[\mathrm{~V}_{\mathrm{ICk}}\right]$; Vectors $\left[\mathrm{PC}_{\mathrm{k}}\right]$ make it possible to build a matrix $[\mathrm{PC}]=\left[\mathrm{PC}_{1}, \mathrm{PC}_{2}, \ldots, \mathrm{PC}_{n}\right]$. The product $[\mathrm{PC}] *\left[\mathrm{~V}_{\mathrm{COg}}\right]$ provides the priority vector $\left[\mathrm{V}_{\mathrm{POg}}\right]$ of the considered $\mathrm{PH}$, of which the largest component VPOg , y) corresponds to the $\mathrm{PH}_{\mathrm{y}}$ chosen.

\section{APPLICATION TO AN INDUSTRIAL CASE STUDY}

\subsection{Description of the production system}

The industrial system used for testing is a mechanical production workshop which manufactures in a recurring way different types of aircraft products, mainly 'shafts' and 'sleeves' of big sizes, having tight tolerances and complex routings. These products are in the core of the dynamics system of the aircraft mechanical engineering manufactured by the company. This workshop comprises about fifteen CNC machining centres. The machines are versatile, of high precision, with important capacities and equipped with all the ad hoc peripheral equipment and tools. Batch size seldom exceeds fifteen products, each product representing a value of several hundred thousand Euros. Throughput time can reach 6 months for the most complex productions.

Various problems are observed in the workshop. Workshop control is derived from a traditional MRP calculation, associated to batch sizes obtained via optimized economic calculation. Cycle times may turn out to be too long, which generates chronic delivery delays. In addition, due to the lack of synchronization, resources remain without occupation part of time and the OEE (Overall Equipment Effectiveness) is weak ( $<$ to $50 \%)$.

\subsection{Downstream Production, production of small renewable series and multicriteria analysis}

\subsubsection{Production of small renewable series}


The workshop operates in Job Shop and produces small renewable series of mechanical parts with high added value. The production in small series is initially a batch production. It differs according to produced quantities. The articles, parts and subsets to be produced are released in small quantities in a repetitive way. However, although they are repetitive, the series are produced in a spaced way and irregularly over time. Products (mechanical part) are generally complex, expensive, using high level technology and have the characteristics to have a very low standardisation level with great diversity.

Product manufacturing is done through successive operations. When an operation is completely finished for a whole batch the following one can be initiated. Thus, overlapping techniques are never used in the production in small series. In this configuration, flows are interspersed with many transport or handling operations. As a result, indirect handling and storage costs are high. The handling organization aims to reduce these costs by changing to the utmost handling and transport ways. The large size of the queues and the direct consequences of flow non optimization make cycle times long compared with operation times. This represents a considerable economic disadvantage for manufacturing companies.

\subsubsection{Link between downstream production and production in small renewable/multicriteria}

\section{series}

In the case of the production of a wide variety of products of large added value in small series, the application of the kanban method would create a very large number of work-in-progress (WIP) stocks whose instantaneous value would be similar to that of the end products. The value of WIP stocks would be very important, which would go against the envisaged objective and, therefore, it is not possible to directly transpose this method.

However, the kanban method is interesting because it relies on calls for production driven by customer orders. It is this concept of 'driven' system that we want to transpose to a production in small and very small series, supported by a proactive control.

We propose an approach in which products advance in the workshop is optimized along the production lines: the principle is based on the way product output orders are organized from the queues in front of each machine. The goal is to support improved flows in the workshop; it is thus necessary to find conditions for creating a downstream call system.

Downstream release will limit advance-made production and production having to wait. It therefore reduces wasting due to waiting times and overproduction. Generally, downstream release is closely related to just in time. Setting up a downstream release system in the case of a production in renewable small series reduces the complexity of control decisions and the already low flow volumes.

This approach can be applied with a method based on estimates allowing creating optimized scheduling according to some criteria. Optimised results can be interesting; however it is necessary to take into account the workshop capacity to react quickly to unforeseen events.

This reactivity must be favoured as much as possible.

This requires a control system organization based on on-line development of product orders in the queues in front of each machine. For this reason, it is necessary to use an automatic method to obtain an order in front of each machine, machine after machine, and taking into account a number of criteria.

The choice of the multicriteria analysis method was studied by (Ounnar, 1999) and led to the Analytic Hierarchy Process (AHP) multicriteria method as it was presented in the section 4.

\subsection{Building the hierarchical decision process}

The main objective is to select the 'best product' to be processed by the resource in case there should be several products in the queue: the best product implies that it has the highest 'multicriteria' priority. This objective enables operation optimization of the queues in front of the resources and reduction of 
costs and manufacturing times of each product of a batch. Time reduction was the general objective of the study since it leads to cost reduction.

When a new product enters a queue, the AHP service indicates the highest priority product of the queue by performing a pair wise comparison of the elements of each level of the hierarchy and by estimating the relative weights between each element of two adjacent levels.

The hierarchical criteria system and the corresponding indicators are presented below by describing the various viewpoints to be jointly analyzed in order to respect the different interests of the interacting holons.

At first, let us examine interests from the 'Resource Holon' point of view. The first criterion (C1) relates to the product type. A resource must before all seek productivity, which minimizes the resource exploitation cost. This can be evaluated through an indicator such as OOE (Overall Equipment Effectiveness) that must be maximized. A strategy consists in avoiding resource downtimes. For that, a way is to supplement the principal production work load by a secondary production with, naturally, less priority. $\mathrm{C} 1$, which binds each $\mathrm{RH}$ to each $\mathrm{PH}$, allows determining priorities for several types of production, according to the class they belong to:

- Principal resource (resource dedicated to the product) or secondary resource (substitution in the case of unavailability of an equivalent resource);

- Regular product (large and medium quantities) or work load complement product (small quantities);

- Product for final assembly or product for spare part.

Associated indicators are qualitative indicators defined by values that are periodically updated by the workshop management:

- I11 (Principal or Secondary Resource) indicates whether resource is principal or secondary; Principal resources have a higher priority than secondary resources; This allows loading machines that are underused with a task carried out under subcontracting for other manufacturing production workshops;

- I12 (Principal Product or Complement) informs if a product belongs to a batch of average to small size or of very small size; Products belonging to a very small size batch have highest priority; In fact, calculation of the quantities to be released leads to batch sizes, but this quickly becomes rather virtual in our approach because scheduling is no longer carried out on complete batches, but individually for each product; Batches can then be reconstituted;

- I13 (Produced for Assembly or Spare Part) indicates if the product is a spare part or if it is affected to the production of finished products; Nominal production will be favoured over spare production which does not have the same synchronization constraints with the production system: for spare parts, delivery periods are longer, they include transportation times and their final use (installation of the part in the machine) depends on the operation mode of the customer.

Values are given to the three indicators in each AHP service and for each product. A priority level is associated to each indicator and is implemented in AHP services.

Criterion C2 relates to a resource work load. The aim is to avoid working without effectiveness. The more a resource work load is raised, the more it becomes relevant to privilege products with high priority. It is also inappropriate to process a product with weak or average priority with a resource when the next resource concerned with the product is overloaded. Criterion C2 is related to a resource occupation rate and allows taking these constraints into consideration. In other cases this criterion will not influence the classification obtained with the AHP algorithm. Indicator I21 (Resource Work Load) associated to this criterion quantifies the rollup of tasks that are on standby in the queue.

Interests are distinct from the 'Product Holon' point of view. Criterion $\mathbf{C 3}$ relates to the progression of the product. Obtaining the minimum cost is a fundamental objective that must be reached for a PH: flow time has to be reduced. Since technological processing times are generally optimized by ad hoc process 
setups, we can effectively act only by minimizing product queue times. If this is systematically carried out in all the WIPs crossed by the products, we obtain the shortest possible average cycle time and thus the lowest production cost. In order to meet this goal, we have developed a strategy aiming at artificially creating a pull system effect. Criterion $\mathrm{C} 3$ allows supporting a $\mathrm{PH}$ with a progress status close to final stage. Let $n$ be the number of data processing runs to be carried out on a $\mathrm{PH}$ and $k$ be the current data processing run of the $\mathrm{PH}$. The closer the $\mathrm{PH}$ is to its completion $(k / n$ near to 1$)$, the more important the priority of this PH will be. Indicator I31, which corresponds to a product global progression $(\mathrm{I} 31=k / n)$, allows accelerating flows throughout its routing. This downstream call is caused by the PH itself. In other words, the PH contributes first to empty the production system, which releases capacity that the RH uses. In order to minimize queue times, indicator I32 (Local Progression) supports the PH flow to the immediate next $\mathrm{RH}$ to process this $\mathrm{PH}$.

This criterion is only applicable in case of online production. Indeed, it results in an overlapping of a batch on two resources. As soon as the first part of the batch leaves a M1 resource and starts being machined by a downstream resource M2, the remaining of the products forming the batch will have highest priority, provided that the product machining time of M1 is higher or equal to the machining time of M2.

Criterion $\mathbf{C 4}$ is the queue time in front of a resource. Various products with different priorities circulate simultaneously in the production system. An important risk would be to forget a product with weak priority in a queue and not to have the possibility to take it out of the queue. Indicator I41 (Queue time) associated to criterion $\mathrm{C} 4$ is made of the $\mathrm{PH}$ queue time in front of a $\mathrm{RH}$ and aims to facilitate the exit of the $\mathrm{PH}$ from the queue if it has been there for a long time by increasing its relative importance.

Finally, from the 'Order Holon' point of view, the fundamental objective is the respect of delivery lead times. Criterion $\mathbf{C 5}$ examines the remaining slack for each $\mathrm{PH}$ : if the number of remaining operations on a $\mathrm{PH}$ is important and if the delivery lead time of the $\mathrm{OH}$ to which it is attached is close, it becomes urgent to give this $\mathrm{PH}$ a high priority with respect to the other PHs. Criterion $\mathrm{C} 5$ allows respecting the delivery lead time of an $\mathrm{OH}$. For an $\mathrm{OH}$ concerning several PHs, we can consider that most of the PHs will be processed in time and that there will remain some late PHs: this criterion aims at accelerating the processing of the late PHs. The associated indicator I51 (Remaining Slack) is given by the formula: I51 = remaining_duration - remaining_phases_duration.

The more the duration of the envisaged phase decreases and the product approaches the exit of the workshop, the higher the priority. Therefore, the smaller the margin, the smaller the latitude and the higher the priority to treat the task The smaller I51 is, the more the concerned PH will be allocated high priority.

The set of all the choices concerning the criteria and associated indicators presented above makes it possible to set up the hierarchical decision structure illustrated in figure 3. Other criteria and indicators could be added.

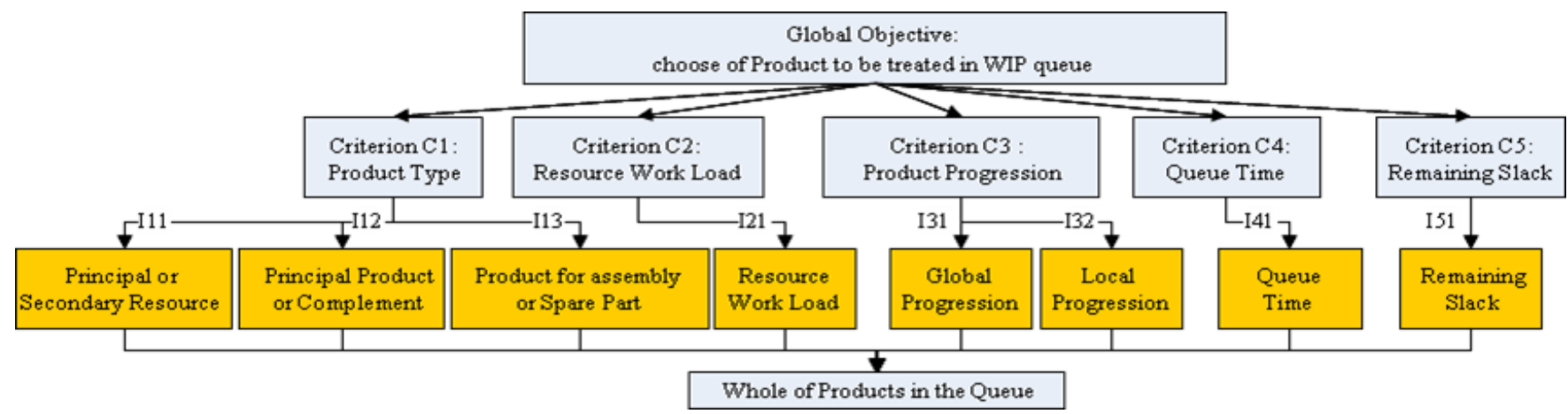

Figure 3. Hierarchical structure of multicriteria decision. 


\subsection{Production workshop modelling and configuration of a simulation prototype}

In order to develop a simulation model of the workshop as realistic as possible, we chose to use an industrial simulation tool: Arena 8.01. The model comprises the general flow organization between resources. It is completely based on the routing file of the 17 products circulating in the production workshop (14 resources). The routing file contains the following information:

- Routing of each product: designation of the resources through which the product will pass;

- Preparation time of each product;

- Machining duration;

- Optimal quantity of each product batch;

- Number of files per product ${ }^{2}$ batch.

The model of each RH allows - starting from a Boolean variable defined at the beginning of simulation to use either a reference queue discipline, or the multicriteria queue discipline, resulting from the AHP algorithm.

Indeed, analysis, modelling under Arena and performance assessment of the production workshop are carried out for the two management approaches. The first model simulates production workshop operation in reference mode. This means that product order on a resource depends only on its arrival in the resource queue. This is true for all the products and all the resources. The second model allows simulating production workshop operation when product order on the resource is established with the AHP algorithm.

The goal of this modelling is to simulate the production workshop in order to make a time related comparative study of the two operations.

Figure 4 presents the global operation on one resource (resource 515). The same operation is done on each resource of the production workshop.

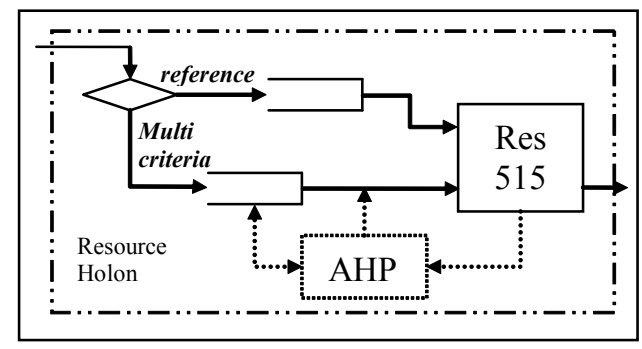

Figure 4. Global operation on resource 515

The model interacts with the AHP service and allows the Arena model to extract the priority product from the corresponding file. In this manner, estimated scheduling is no more possible. The decision centre and the control decision-making centre of the workshop are now decentralized at the level of each resource. Thus, resources self-organize and manage in real time the sequence of tasks.

It is shown below how the criteria / indicators hierarchical system described above is regulated and then, how the Arena data are used on resource 515. It is necessary to start with the setup of the AHP algorithm.

\section{AHP Configuration phase:}

Each resource has its own parameterization, but the relative importance matrix between criteria [C] (Table 2) is constant for all the RHs.

\footnotetext{
${ }^{2}$ All information concerning the work to be performed is attached to the concept of work order (WO). Release is made through the edition and the release of a manufacturing file, related to a WO, and which contains all relevant information for operators.
} 


$[\mathrm{C}]=\mid$\begin{tabular}{ccccc|cc}
$\mathbf{C 1}$ & $\mathbf{C 2}$ & $\mathbf{C 3}$ & $\mathbf{C 4}$ & $\mathbf{C 5}$ & & \\
$\downarrow$ & $\downarrow$ & $\downarrow$ & $\downarrow$ & $\downarrow$ & & \\
1 & $1 / 3$ & $1 / 3$ & 3 & 1 & & $\leftarrow$ \\
3 & 1 & 1 & 9 & 3 & & $\mathbf{C 1}$ \\
3 & 1 & 1 & 9 & 3 & $\leftarrow$ & $\mathbf{C 2}$ \\
$1 / 3$ & $1 / 9$ & $1 / 9$ & 1 & $1 / 3$ & $\leftarrow$ & $\mathbf{C 4}$ \\
1 & $1 / 3$ & $1 / 3$ & 3 & 1 & $\leftarrow$ & $\mathbf{C 5}$
\end{tabular}

Table 2. Relative importance matrix between criteria $[\mathrm{C}]$.

The following vector of criteria relative importance in regard to the global objective is obtained:

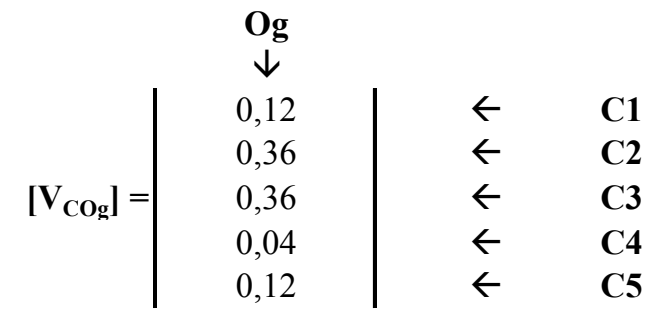

It is the same principle for the relative importance matrices $\left[I_{C k}\right]$ between indicators: $I_{C 1}$ and $I_{C 3}$ (Table $3)$. The parameterization of the $\left[\mathrm{I}_{\mathrm{Ck}}\right]$ matrices is specific to each $\mathrm{RH}$. The following results concern as an example the resource $n^{\circ} 515$.

$$
\left[\mathbf{I}_{\mathbf{C} 1}\right]=\mid \begin{array}{ccc|cc}
\mathbf{I}_{11} & \mathbf{I}_{12} & \mathbf{I}_{13} & & \\
\downarrow & \downarrow & \downarrow & & \\
1 & 1 / 3 & 1 / 3 & \leftarrow & \mathbf{I}_{11} \\
3 & 1 & 1 & \leftarrow & \mathbf{I}_{12} \\
3 & 1 & 1 & \leftarrow & \mathbf{I}_{13}
\end{array}
$$

Table 3. Relative importance matrix $\left[\mathrm{I}_{\mathrm{C} 1}\right]\left[\mathrm{I}_{\mathrm{C} 3}\right]$ for $\mathrm{RH} \mathrm{n}^{\circ} 515$.

The following vector of indicators relative importance with regard to criterion $\mathrm{C} 1$ is obtained:

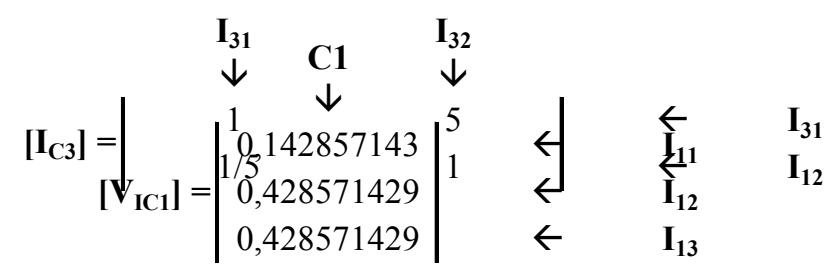

The following vector of indicators relative importance with regard to criterion $\mathrm{C} 3$ is obtained:

$$
\begin{aligned}
& \text { C3 }
\end{aligned}
$$

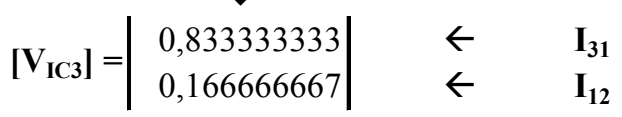


$\left[\mathrm{I}_{\mathrm{C} 2}\right]=\left[\mathrm{I}_{\mathrm{C} 4}\right]=[1]$ (one indicator for these criteria). In this case, the associated vector of indicators relative importance with regard to criteria $\mathrm{C} 2$ and $\mathrm{C} 4$ are: $\left[\mathrm{V}_{\mathrm{IC} 2}\right]=\left[\mathrm{V}_{\mathrm{IC} 4}\right]=[1]$.

\subsection{Experiments and obtained results}

\section{AHP Dynamic phase:}

The relative importance matrices $\left[\mathrm{P}_{\mathrm{kx}}\right]$ between alternatives for an indicator have variable dimension according to the number of PHs in WIPs. The dimension already depends on the number of the types of different products having to use the resource. The matrix elements $\mathrm{p}_{\mathrm{kx} ; \mathrm{ij}}$ are directly calculated from the indicators values. These values are either preset values or computed from the attributes of certain components of the simulation model:

$\mathrm{I}_{11}=1$ if the product is principal

$\mathrm{I}_{11}=0.5$ if the product is secondary

$\mathrm{I}_{12}=1$ if the product belongs to a very small batch

$\mathrm{I}_{12}=0.5$ if the product belongs to a small or average batch size

$\mathrm{I}_{13}=1$ if the product is allocated to the production of finished products

$\mathrm{I}_{13}=0.5$ if the product is a spare part

$\mathrm{I}_{21}, \mathrm{I}_{31}$ and $\mathrm{I}_{32}$ are calculated from the routing file including $\mathrm{PH}$ information: chronology of used resources and associated operational times.

$\mathrm{I}_{41}$ and $\mathrm{I}_{51}$ are generated in real time by the Arena model.

Indeed, the Arena simulation is coupled with a calculation module developed under Excel. The various necessary data $(\mathrm{PH}, \mathrm{OH})$ concerning the WIP standby products are collected in the Arena model and then exported into a specific Excel sheet to each RH. The AHP algorithm of the RH is programmed in the same Excel file. Calculation updating is done by the introduction of new data in the sheet. The result of the multicriteria classification is then imported again in the Arena model and used to select the good $\mathrm{PH}$ in the queue for continuing the simulation. The corresponding product is then treated by the simulation model of the resource.

As an example for this step, the [ $\left.\mathrm{P}_{11}\right]$ matrix (relative importance between the alternatives; products named part $x$ ) is presented in table 4 . The number $\mathrm{N}$ of the considered alternatives corresponds to the products number in the WIP. Therefore, the considered alternatives presented in table 4 shows the WIP state at a decision date: $\mathrm{WIP}=$ \{part_27, part_28, part_32, part_34, part_41, part_42, part_43, part_45, part_47\} and $\mathrm{N}=9$.

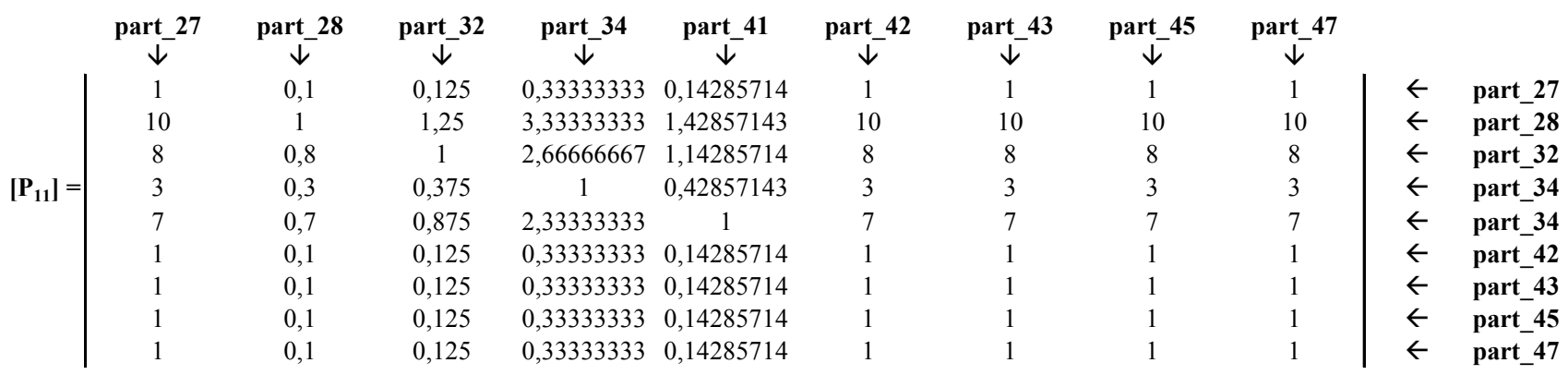

Table 4. Example of $\left[\mathrm{P}_{11}\right]$ matrix for $\mathrm{RH} \mathrm{n}^{\circ} 515$.

The following vector of alternatives relative importance (products named part $\_$) with regard to the indicator $\mathrm{I}_{11}$ is obtained: 


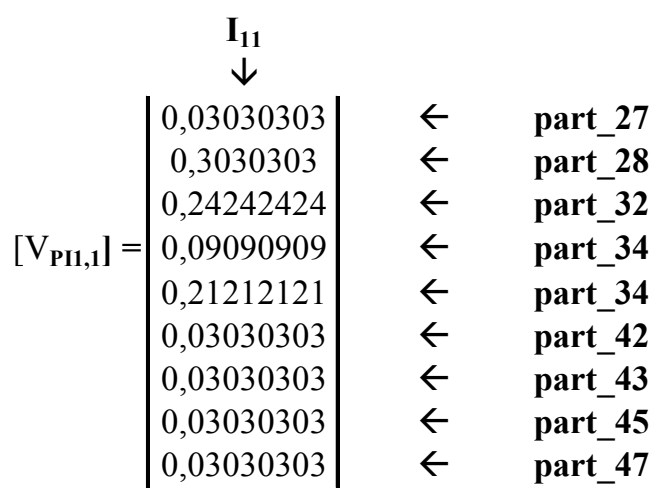

It is the same principle for the relative importance matrices between the alternatives $\left[\mathrm{P}_{\mathrm{kx}}\right]: \mathrm{P}_{12}, \mathrm{P}_{13}, \mathrm{P}_{21}$, $\mathrm{P}_{31}, \mathrm{P}_{32}, \mathrm{P}_{41}, \mathrm{P}_{51}$ and the corresponding vectors of relative importance of the alternatives (products named part $x$ ) with regard to the indicators: $\mathrm{V}_{\mathrm{PI} 1,2}, \mathrm{~V}_{\mathrm{PI} 1,3}, \mathrm{~V}_{\mathrm{PI} 2,1}, \mathrm{~V}_{\mathrm{PI} 3,1}, \mathrm{~V}_{\mathrm{PI} 3,2}, \mathrm{~V}_{\mathrm{PI} 4,1}, \mathrm{~V}_{\mathrm{PI} 5,1}$.

Then, matrix $\left[\mathrm{PI}_{\mathrm{k}}\right]$ is built with each column being a vector $\left[\mathrm{V}_{\mathrm{PIk}, \mathrm{X}}\right]$. The $\left[\mathrm{PI}_{1}\right]$ matrix is shown below (Table 5):

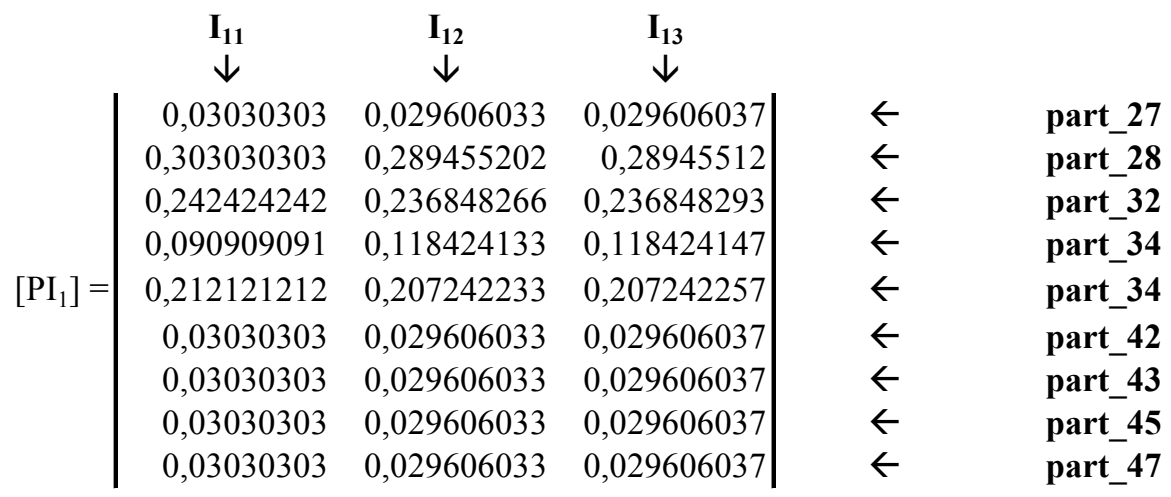

Table 5. $\left[\mathrm{PI}_{1}\right]$ matrix for $\mathrm{RH} \mathrm{n}^{\circ} 515$.

After that, a vector giving the products relative importance compared to the criteria is built for each criterion: $\left[\mathrm{PC}_{\mathrm{k}}\right]=\left[\mathrm{PI}_{\mathrm{k}}\right] *\left[\mathrm{~V}_{\mathrm{ICk}}\right]$. A matrix is built with the $\left[\mathrm{PC}_{\mathrm{k}}\right]$ vectors: $[\mathrm{PC}]=\left[\mathrm{PC}_{1}, \mathrm{PC}_{2}, \ldots, \mathrm{PC}_{\mathrm{n}}\right]$.

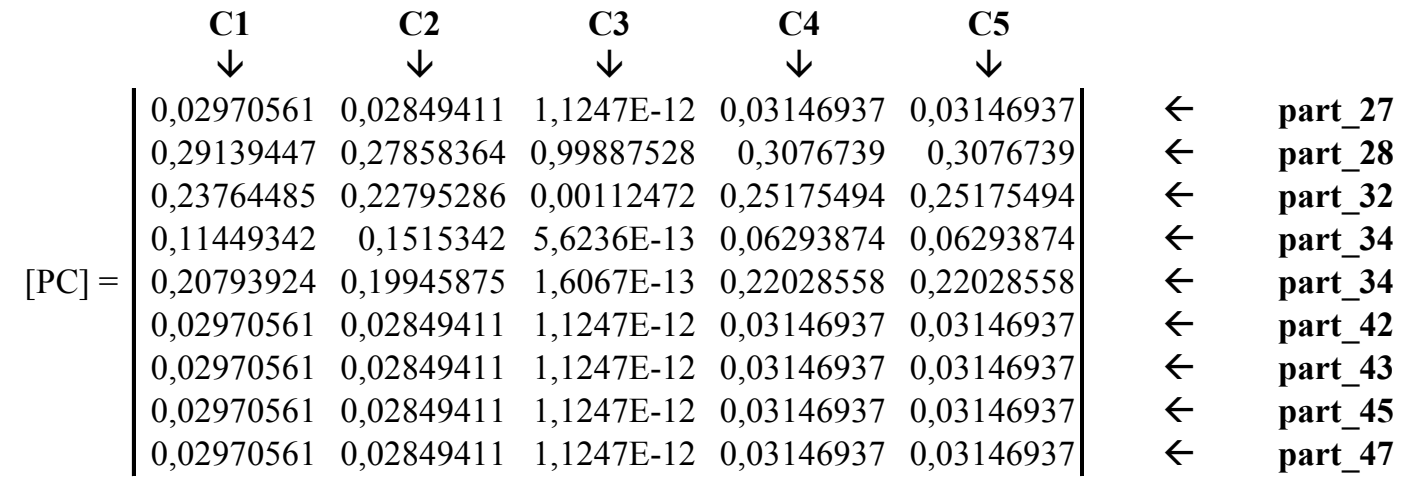

Table 6. [PC] for $\mathrm{RH} \mathrm{n}^{\circ} 515$.

The product $[\mathrm{PC}] *\left[\mathrm{~V}_{\mathrm{COg}}\right]$ provides the priority vector $\left[\mathrm{V}_{\mathrm{POg}}\right]$ of the considered $\mathrm{PH}$, of which the largest component VPOg ) corresponds to the $\mathrm{PH}_{\mathrm{y}}$ chosen. 


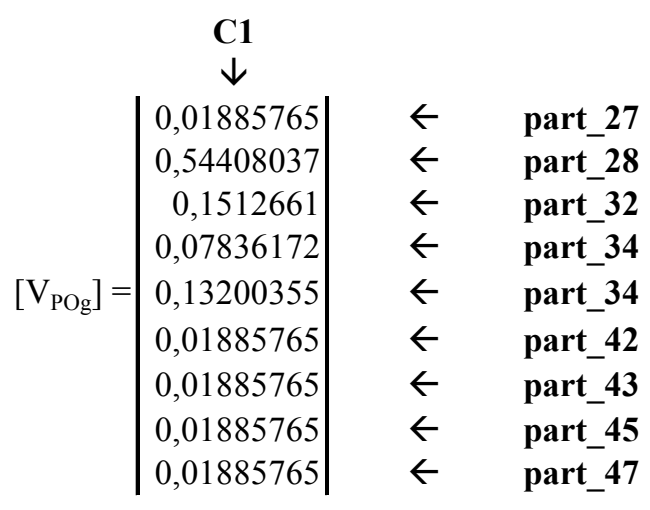

For this treated example, the chosen product is the 'part_28'.

The experiments used a data file corresponding to 18 months of the real production workshop. This pilot period is sufficiently large to put in evidence the diversity of production situations. In addition, the production being already done, the production workshop real performance was known in term of productivity.

Only product and resource names were made anonymous. We thus used the same release dates as those of the real production. One modification was done with the transformation of batches $i$ of size $\mathrm{n}_{\mathrm{i}}$ to $\mathrm{n}_{\mathrm{i}}$ batches of unit size.

This corresponds to supporting one part flow production approach, which is more fluid than the economic batch sizing traditional approach which generates synchronization task problems degrading the OEE.

The experiments were carried out under the conditions described in section 5.4 with systematic comparison between the two disciplines. In the case of experiments carried out with a FIFO discipline, the products are treated sequentially by the resource, according to the arrival order in the WIP stock. In addition, the use of a strategy 'batches of unit size' alone gives an equivalent productivity than the best of scheduling-by-batch heuristics used in the real production workshop. These strategy (FIFO \& unit size batch) correspond to the reference discipline. In the case of multicriteria discipline experiments, the choice of the Product Holon to be treated by each Resource Holon is done in real time, i.e. during the simulation.

When the resource finishes the preceding product, it is thus necessary to choose the following product by using the AHP algorithm.

Figure 5 presents average results over the 18 month period: a comparison of the outputs of the two disciplines is presented. Only products of the 'shaft' type assigned to the production workshop are indicated. 'Sleeve' type products give similar results and additional products are not concerned with productivity criteria. These results show lead time reduction for the all the products. Only one discrepancy appears with product 'part_14'. It turned out that this product corresponds to a marginal production, in small quantities, for aircraft maintainability: part_14 is a rare spared product.

In the case of experiments carried out with the reference discipline, we have obtained an average total time of $1304.53 \mathrm{~h}$, an average queue time of $697.93 \mathrm{~h}$ and an OEE of $46.49 \%$.

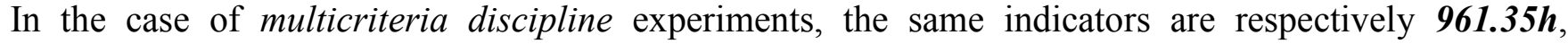
$354,32 \mathrm{~h}$ and $\mathrm{OEE}=\mathbf{6 3 . 1 4 \%}$. For the whole production, we have observed a reduction larger than $25 \%$ of the average production time, for all the products and by taking into account the quantities.

This improvement is entirely due to the very strong reduction of queue times, about $50 \%$ on average. This results in an OEE progression of $35 \%$. 


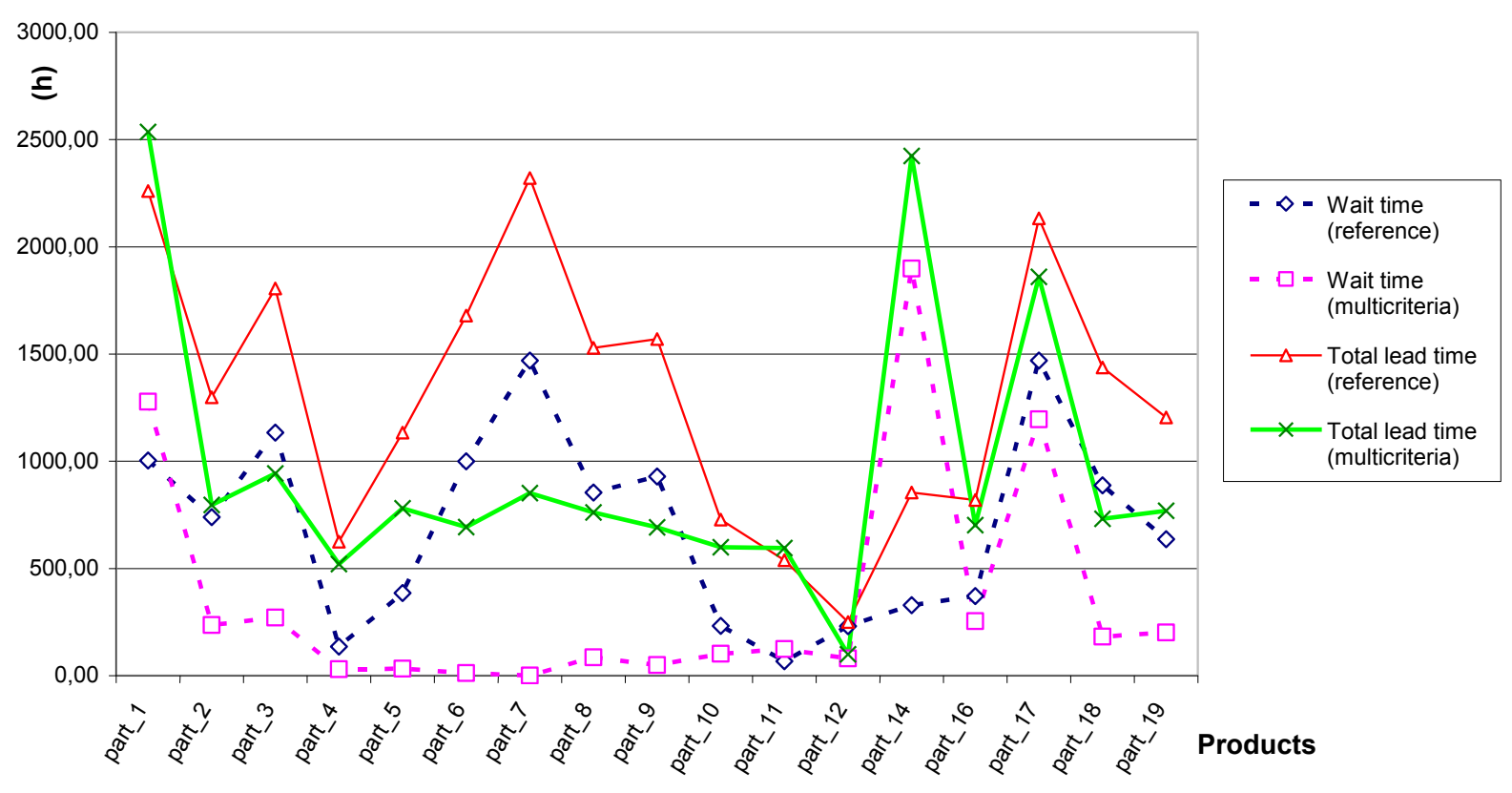

Figure 5. Comparison of the 2 WIP management disciplines.

\section{CONCLUSION}

We have proposed a control system based on a holonic and isoarchic approach. For each Resource Holon, the multicriteria decision mode via AHP allows choosing in real time, among the standby Product Holons, the one whose treatment supports the flows. This leads to reduce production durations, WIP volumes and costs associated to Order Holons. The AHP algorithm implemented by each Resource Holon has been presented and the strategy developed to artificially create a pull flow effect has been explained. One of the criteria, considered as fundamental in our multicriteria analysis, allows favouring products whose progress state is close to the final state. The first results obtained on a complex industrial case are promising: even if they certainly can be improved, they show unambiguously the interest of holonic, isoarchic and multicriteria control compared to the traditional approaches. In addition, we intend to test new criteria. The presented work represents the premises of a new control research orientation. Many improvements will be made at the functional level with consideration of new criteria related to PHs, RHs and OHs, as well as at the technological level with the implementation of a demonstrator using distributed simulation. We will then work on the analysis of results variability.

\section{REFERENCES}

Bongaerts L., L. Monostori, D. McFarlane, B. Kadar, 2000. Hierarchy in distributed shop floor control, Computers In Industry, 43, p. 123-137.

Brun-Picard D., 1988. Contribution à l'élaboration d'un modèle de commande décentralisée. Thèse de Doctorat es Sciences, Université d'Aix-Marseille III

Koestler A., 1967. The Ghost in the Machine, Hutchinson, London.

Harker P.T., 1989, The art and science of decision making: The Analytic Hierarchy Process: Applications and Studies. Springer-Verlag Ed.

Hsieh F.S., 2008. Holarchy formation and optimization in holonic manufacturing systems with contract net, Automatica, Vol. 44 (4), pp. 959-970. 
Leitao P., F. Restivo, 2006. ADACOR: A holonic architecture for agile and adaptive manufacturing control, Computers in Industry 57, p. 121-130.

Maturana F., W.Shen, D.H. Norrie, 1999. 'MetaMorph : An adaptive agent-based architecture for intelligent manufacturing' International Journal of Production Research. Volume 37, Number 10.

Mathews J. 1995. Organizational foundations of intelligent manufacturing systems - the holonic viewpoint. Computer Integrated Manufacturing Systems, 8(4), p. 237-243.

Mesarović M. D., D. Macko, Y. Takahara, 1980. Théorie des systèmes hiérarchiques à niveaux multiples, Economica, Paris, 1980.

Ounnar F., 1999. Prise en compte des aspects décision dans la modélisation par réseaux de Petri des systèmes flexibles de production. PhD, INPG - Grenoble.

Ounnar F., Pujo P., Mekaouche L., Giambiasi N., 2007. Customer-supplier relation-ship management in an intelligent supply chain network. Production Planning \& Control, 18(5), p. 377-387.

Ounnar F., Pujo P., Mekaouche L., Giambiasi N., 2008. Integration of a flat holonic form in an HLA environment, Journal of Intelligent Manufacturing, DOI: 10.1007/s10845-008-0106-4

Pujo P., F. Ounnar, 2007. Vers une approche holonique des systèmes mécatroniques complexes Proposition d'un système de pilotage auto-organisé et isoarchique, JESA, 41 (6), p. 673-706.

Saaty T., 1980. The Analytic Hierarchy Process, Mc Hill.

Smith. R.G., 1980. The contract net protocol: high level communication and control in a distributed problem solver. IEEE Transactions on Computers, Vol. 29, pp. 1104-1113.

Van Brussel H., J. Wyns, P. Valkenaers, L. Bongaerts, P. Peeters, 1998. Reference architecture for holonic manufacturing systems: PROSA, Computers in Industry, 37, p. 255-274.

Vargas L.G., 1990, An Overview of the Analytic Hierarchy Process and its Applications. European Journal of Operational Research, 48, pp. 2-8.

Wedley W.C., 1990, Combining Qualitative and Quantitative Factors - An Analytic Hierarchy Approach. Socio Economic Planning Sciences, 24, (1), pp. 57-64. 